\title{
The Role of Members of School Management Teams in Curriculum Implementation and Management: A Case Study of Selected Schools in the Gauteng Province (Republic of South Africa)
}

Tebogo Mogashoa

\author{
College of Education, University of South Africa
}

Email: mogasti@unisa.ac.za

\author{
Doi:10.5901/mjss.2013.v4n14p135
}

\begin{abstract}
The aim of the research was to establish the role that members of the school management teams (SMTs) play in terms of curriculum implementation and management. The qualitative method was used to gather information from members of the SMTs on how the new curriculum is implemented and managed. In-depth formal interviewing was used as the main data collection method. The researcher used focus group interviews and individual interviews to collect data. Comparisons were drawn, similarities identified and a discussion of the research was presented. The data were coded, categorised and condensed. The researcher then interpreted and drew meaning from the displayed data. The study revealed that members of the SMTs had different views about their role as implementers and managers of the curriculum. SMTs have received training through workshops organised by the Department of Education on Curriculum 2005 (C2005), the Revised National Curriculum Statement (RNCS), and the National Curriculum Statement (NCS) as well the Curriculum and Assessment Policy Statement (CAPS). Thus most of the members of the SMTs felt that they have been empowered by the training they received. They also felt that it is imperative to make sure that the school environment be conducive for learning and teaching to take place and ensure the successful implementation and management of the curriculum. However, the study also revealed challenges and recommend that policy- makers have to explore professional development from the perspective of the SMTs in order to clearly understand what would be best for changing their curriculum implementation and management.
\end{abstract}

Keywords: Curriculum, involvement, evaluation and assessment, critical discourse analysis, perceptions, forms of assessment, assessment tasks, progression and promotion.

\section{Introduction and Context of the Study}

The birth of democracy in 1994 led to the establishment of a new dispensation and a need for the democratisation of the education system. The apartheid education system has disadvantaged the majority of South Africans especially the black communities. There was consensus among stakeholders that there has to be transformation in the education system in South Africa. This led to the introduction of C2005 with an emphasis on outcomes-based education.

The Department of Education adopted a transformative approach to teaching and learning with the endorsement of outcomes-based education with its emphasis on critical outcomes. Critical outcomes are broad educational goals or a set of skills, attitudes and knowledge that all learners should demonstrate after participating in the learning and teaching process. With the new education system the government endeavoured to cater for all its citizens regardless of race, culture, gender, creed or religion.

C2005 was piloted in selected schools countrywide in 1997. Then, in 1998, the Department of Education introduced C2005 at all schools across South Africa. The introduction of outcomes-based education made many demands on both the members of the SMTs and the education system. SMTs had to change the way they implemented and managed the curriculum. In 2000, C2005 was reviewed. The review committee recommended that the curriculum required strengthening and that can be attained through streamlining of its design features. They produced an amended NCS. However, in July 2009 another task team was established by the Minister of Basic Education to investigate the nature of the challenges and problems experienced in the implementation of the NCS and to develop a set of recommendations designed to improve the implementation of the NCS. The Task Team came up with a document that it recommended it should replace the NCS and it is called CAPS.

According to Samuels (2009:1), research is designed to solve a particular existing problem so that there is a much larger audience eager to support research that is likely to be profitable or solve problems of immediate concern. Based 
on research, management can make intelligent and informed decisions (Moorty 2010:1). It is hoped that the study will also inform policy makers about problems experienced by members of the SMTs with regard to the implementation and management of the curriculum. Policy makers and decision-making bodies could use the outputs of this study to shape the education system in future. An assessment policy can have a negative impact on teaching and learning if not appropriately implemented and managed. Drotar (2007:3) states that in order for research to be significant, the research needs to exceed the threshold of current scientific work in a specific area. The knowledge this research intends to create will be of significance because members of the SMTs play a key role in curriculum implementation and management.

\section{Theoretical Frameworks}

According to Terre Blanch (2008:20), refining a research problem involves identifying a theoretical framework upon which to base the research. This study was underpinned by a critical discourse analysis theory in which the researcher expressed his comments or judgments based on written or spoken communications, discussions or conversations with members of SMTs. South Africa's political history has influenced the theories of the ruling party about the education system and has had an impact on its decision to design and develop a new curriculum. In this study it is argued that political decisions and perspectives on changes to the curriculum have to be supported by written educational theories and perspectives. According to Van Dijk (2006:252) critical discourse analysis is primarily interested and motivated by pressing social issues, which it hopes to better understand through discourse analysis. The framework of analysis includes analysis of texts, interactions, and social practices at the local, institutional, and societal levels.

The main research question is as follows:

* What are the roles of members of the SMTs in curriculum implementation and management?

\section{Reseach Design and Methods}

Trochim (2008:1), states that research design provides the glue that holds the research project together and design is used to structure the research, to show all the major parts of the research project: the samples or groups, measures, treatments or programmes, and methods of assessment- work together to try to address the central research questions. Tompkins (2008:4) further states that researchers can design a study to characterise a single instance of a phenomenon or take an inference about a phenomenon in a population via a sample. The research methodology applied in this study was based on qualitative and inductive data analysis. Qualitative research assisted the researcher to investigate how members of the SMTs manage curriculum implementation.

The target group and population of the study comprised experienced members of the SMTs, who managed the implementation of C2005, NCS and CAPS. Only five schools in the Gauteng Department of Education's Gauteng North District were invited to participate in the study. The above description of the sample is an indication that a purposive sample was used in this research. According to Soanes and Stevenson (2008:1167) purposive refers to "having or done with a particular purpose". Zint and Montgomery (2007:3) state that purposeful sampling is a non-random method of sampling, where the researcher selects information rich cases to study in depth. According to Voce (2005:6), the primary methods of data collection in qualitative research are observations, interviews and focus group discussions. In this study purposeful sampling was used to select informants with rich information. In-depth formal interviewing was used as the main data collection method.

\section{Data Analysis}

According to Michelle (2007:3), qualitative data analysis consists of identifying, coding and categorising patterns found in the data. Bradley (2007:5) declares that once the data have been reviewed and there is a general understanding of the scope and contexts of the key experiences under investigation, coding provides the analyst with a formal system to organise data, uncovering and documenting additional links within and between concepts and experiences described in the data. Plooy (2007:41) defines data analysis as a process of bringing order and structure to the mass of collected data. In this study data analysis and interpretation involved the analysis and interpretation of documents related to curriculum policies. Data were analysed by selecting, comparing, synthesising and interpreting information to provide explanation. The researcher used the inductive approach to ensure that the research findings emerge from the frequent, dominant or significant themes inherent in raw data generated. 


\section{Research Findings and Discussions}

\subsection{Question: Please comment on the role of the SMTs in the implementation and management of the curriculum.}

Members of the SMTs had different views of their roles in curriculum implementation and management. In response to the question above, one participant said, "There are a number of duties that we must perform. Eh, my understanding is that the roles of SMTs have changed drastically and many SMTs have been confused."

Another participant said, "I think there are guidelines. These guidelines help us to understand what the department expect of us and how we should go about as we do our business. They also help us to do our work professionally". Furthermore, a different participant said, "The first thing is eh, it's a big frustration as the education policies change and it makes the management of the school very difficult and the teachers frustrated. If the teachers are frustrated, the child will not benefit. The other thing is that even the people who give us these duties do not agree with one another. When you ask them how this type of curriculum should be implemented, they say you can interpret it yourself. This is devastating".

Another view by a participant was as follows: - "I don't know but I will try. We have policy guidelines which help us with the day to day running of the school. There are policies like code of conduct for the learners, maintenance, to make sure that the school is managed properly, religious policy to make sure that you don't discriminate, and safety policy to make sure that the learners are safe at school. Prior 1994 curriculum guidelines were given to us but now we develop our own guidelines".

Based on the responses of the participants in this study, it is clear that they had different views about the role they play on the implementation and management of the curriculum. This was evident when one participant indicated that the role of SMTs has changed drastically and many SMTs have been confused. The same sentiments were echoed by another participant who stated that the new curriculum caused considerable frustration and has resulted in difficulties and frustration in the everyday management of the school. On the other hand, another participant stated that the new policy guidelines are good and they helped them to understand policies and to do their work professionally. However, another participant was not even sure what "roles" were. This was evident when she indicated that she does not know policy guidelines but will try to respond to the question. The researcher' assumption was that the members of the SMTs' knowledge of their roles were questionable.

The above responses were followed by another question about the type of training that the members of the SMTs had received.

\subsection{Question: What training/development did you receive in respect of curriculum implementation and management?}

The participants mentioned that they had attended some training workshops. This was confirmed by a participant who said, "In terms of curriculum implementation and management, we attended a number of trainings. We were trained on OBE, RNCS, and NCS and now we were trained on CAPS." Another participant acknowledged that they attended some workshops. These were her words:

\footnotetext{
"This happened after school hours. The trainings started around $3 \mathrm{pm}$ to $5 \mathrm{pm}$. Most SMT members do not even have transport. When they arrived at the meetings, it was almost over. They must at least be with us the whole day to explain these policies." The above responses were supported by another participant who said, "They bring workshops to us. They train us on how to implement and manage these policies. They give us guidelines."
}

However, another participant had a different view when he said, "Eh, it was on the job-training but not specific training on curriculum implementation and management. We read policies ourselves and implement them. To say we were going to be trained on policies, no, no! It was not a formal training."

Some of the participants mentioned that they were empowered by the training they attended. This was echoed by one member who said, "I can now manage the curriculum because I was trained." The same sentiments were emphasised by another participant when she said, "Its positive you know, it empowers us so that we know what is expected of us. They make us to be able to work with the community."

However, another SMT member mentioned a different view when he said, "The only thing that I gained is that I must do this and if not, there will be problems. They will charge you. If you are incapable to interpret policies you will be charged. The principal at the end of the day becomes the victim of the policies. Policies are being imposed, end of story."

All participants in this study indicated that they had attended some training workshops. However, the participants had different views about how the training empowered them. Some indicated that they were expected to read and 
implement the policies though they had difficulties in interpreting them. Judging from the responses, it became clear to the researcher that the amount of training was not sufficient for the participants to work through these policies. The analysis revealed that the SMTs were trained for less than three hours a day, over a period of three days. It is clear that the time allocated for training was inadequate for them to understand most of the contents of the policies. On the other hand, one of the members of the SMTs indicated that he was well empowered and can manage the curriculum. However, when the participant was questioned further, he could not reveal the knowledge he had in terms of the roles he should perform in terms of curriculum implementation and management. That was evident when the participant then indicated that the policies were imposed on them.

The next question was asked to establish the kind of support and guidance the participants provided to teachers.

\subsection{Question: How do you provide the necessary guidance and support to the teachers?}

The common response to this question was that the SMT members gave guidance and support to the teachers. A few of the verbatim responses are indicated below:

"I do encourage them to attend workshops. I sometimes organise internal in-service training. We get motivational speakers and we sometimes identify some issues that affect us as a school, then we check if we can involve the district office."

"Yes, upon arrival at the school after training we sit and consolidate what we have received. Then we have common understanding and we implement what we have planned. So far it worked for us."

"The principal should always read in order to empower himself. The problem is that the people who should put the policies into place are not empowered enough. Every morning we have a staff meeting for half an hour, which is compulsory. In these meetings we discuss about policies and other issues of the school."

The data presented by participants indicated that teachers were fully supported. This was evident when one participant stated that she always encouraged teachers to attend workshops and that some internal in-service training were organised in order to support them. It was indicated that in some of the schools there was compulsory meeting every morning to create an opportunity to attend to educators' challenges and needs, including those associated with the implementation of the curriculum.

The next question sought to establish the kind of relationships members of the SMTs have with the teachers in their schools.

\subsection{Question: How are your interpersonal relations with the teachers in your school?}

Most [participants mentioned that they had a good relationship with the teachers in their schools. One member of the SMTs said, "To me to be a principal is nothing. You must lead from behind. I encourage the teachers to always study further. I am very strict and they know that but I am fair and firm. We have a very good professional relationship". The good relations that exist between the participants and the teachers was further emphasised by another participant who said, "I can say that I am one of the lucky ones because when we sit down and have a common understanding, and then we have good relationships. You have problems if people do not understand." This was further echoed by one of the participants who also mentioned that if teachers knew what was expected of them and felt supported, the relationship will always be good. Another participant indicated that he does not compromise on policies for the sake of maintaining good relationship with teachers.

The next question was asked to determine how members of the SMTs ensure that the environment in their schools is conducive for curriculum implementation and management.

\subsection{Question: How do you ensure that the school environment is conducive for curriculum implementation and management?}

All participants indicated that it is imperative to make sure that the school environment is conducive for learning and teaching to take place. The following were some of the verbatim responses to the question above:

"Support, you give teachers support. You make sure that learners are on time and make sure that the teachers maintain discipline in their classes. You encourage the teachers that it is important to be in class all the time. I also make use of prefects who will go and call the teacher if he is not in class. We even have teachers who pray for those 


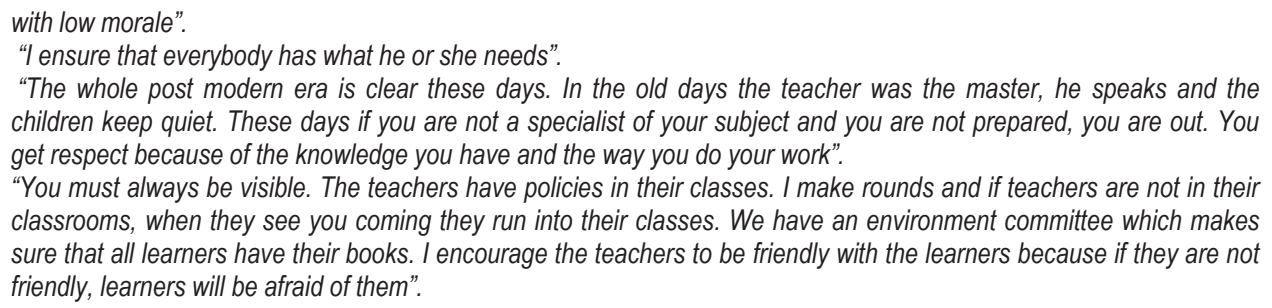

All the participants believe that the school environment should be conducive for teaching and learning to take place. Furthermore, there was evidence in this study that the participants promoted an environment of discipline and friendliness in their schools. Data indicated that the SMTs made sure that learners were on time for their classes and that the teachers maintained discipline. An indication was also made that teachers should be specialists in their learning areas/subjects and that they should be friendly towards the learners.

The next question sought to establish how participants assisted teachers to access information on curriculum issues.

\subsection{Question: How do you assist teachers to access information on curriculum matters?}

The SMT members indicated that HODs made sure that teachers have everything that they needed to successfully implement the curriculum. However, one participant mentioned that the resources are not adequate. He further indicated that at his school they needed to make copies of books and worksheets but the printing machine was broken. He stated that they don't have enough textbooks or money. The other participants mentioned that the Department of Education supplied them with the curriculum documents they needed and that they also used the internet to access websites that provided them with information about curriculum matters. This statement was further supported by other participants who confirmed that they had libraries where they could get access to curriculum documents and that they also used Gauteng online to acquaint themselves with curriculum issues. One member further indicated that although teachers were sometimes reluctant to look for information, it is available.

The above responses were followed by another question to determine how the participants encouraged teachers to reflect on and examine the level of success with regard to curriculum implementation.

\subsection{Question: How do you encourage teachers to reflect on and examine their teaching practice in the light of the new curriculum?}

Participants indicated that they normally discuss challenges during the daily morning meetings. They mentioned that at meetings teachers reflected on any challenges that they have. Some participants indicated that they also used Mondays, which were reserved for teachers to interact, do preparations and assist one another. Another participant mentioned that they usually meet once a month to reflect on what achieved and the challenges that still remain and colleagues help one another by advising on how to overcome some challenges.

In an effort to establish the availability of teaching resources, the following question was asked:

\subsection{Question: What teaching resources are available for teachers to use?}

Participants indicated that the resources are adequate, but that it all depended on whether teachers these recourses effectively or not. This statement was further supported by another participant who said, "We have computers which everybody has access to. We have access to internet. The Department of Education has also supplied every teacher with policy documents". This was also supported by another participant who said, "The largest part of our budget goes to resources. At the beginning of the year I call all the teachers to tell me all things they need to become good teachers. We have computers, books in the library and many teaching and learning aids. The resources are adequate."

The researcher in this study found that the manner in which the members of the SMTs responded to the questions showed that the resources in some schools were adequate. This was evident when one participant indicated that the largest part of their budget was spent on the resources. 


\subsection{Question: What policy does the school have on assessment?}

The data presented by the participants in this study indicated that the Department of Education supplied all schools with assessment policy documents. However, the issue was with regard to the interpretation of these documents as shown by the participants' different concerns. One participant indicated that he was not happy with the assessment policies, because some learners are just being promoted from one grade to the other. On the other hand, another participant mentioned that at the beginning of the school year they received the mark sheets from the Department of Education and they had to do all the exercises such as exams and orals. Contrary to the previously mentioned statements, another participant stated that each school had its own learning area/subject policies on assessment. The researcher in this study reached the conclusion that the participants interpreted assessment policies differently.

\section{Conclusions and Recommendations}

SMTs were supportive in some schools while other schools did not have any SMTs. Schools in urban areas were adequately supplied with teaching and learning support materials compared to schools in rural areas. Members of SMTs' contradicting views were an indication that they did not understand their roles as curriculum implementers and managers. The Department of Education have provided schools with resources to assist with curriculum implementation and management. However, schools did not receive the resources equally or equitably. Though the Department of Education provided schools with assessment policies, members of the SMTs interpreted them differently.

The recommendations are that the Department of Education train SMTs on how to monitor, evaluate and support teachers in terms of new teaching methodologies. Schools should be provided with sufficient infrastructure that allows easy access to resources for the SMTs, teachers and learners. The Department of Education is encouraged to give more financial support to schools in order to provide for basic infrastructure. Policy makers also have to explore professional development from the perspective of the members of the SMTs in order to clearly understand what would be best for changing their curriculum implementation and management. It is therefore recommended that for effective implementation and management of curriculum, the Department of Education should provide adequate knowledgeable curriculum staff to do extensive training with SMTs. SMTs should collaborate and establish curriculum and management clusters to resolve mutual curriculum challenges.

\section{References}

Bradley, E.H. et al. 2007. Qualitative Data Analysis for Health Services Research. Health Services Research. Vol.156: 618-626.

Drotor, D. 2007. Thoughts on Establishing Research Significance and Preserving Scientific Integrity. Oxford Journals. Vol. 33:1-5. Michelle, B. 2007. Data Analysis Strategies for Qualitative Research- Research Corner. AORN Journal. Vol. 7: 103-115. Moorty, S. 2010. The Significance of research in Business Decision Making. Thousand Oaks, CA: Sage.

Plooy, G.M. 2007. Communications Research Techniques, Methods and Implications. Claremont. Juta and Co. Ltd.

Samuels, P. 2009. The importance of research- Why we do research? London. Sage Publications.

Soanes, C. and Stevenson, A. 2008. Concise Oxford English Dictionary. Oxford. Oxford University Press.

Terre Blanche, 2008. Research in Practice: Applied methods for the social sciences. Sandston. Juda Academy.

Tompkins, W.G. 2008. Research Designs: Choosing and Fine-tuning a Design for your Study. London. Sage Publications.

Trochim, W.M. 2006. Research Methods Knowledge Base 2nd Edition. Cincinnati. Atomic Dog Publications.

Van Dijk, T.A. 2006. Principles of Critical Discourse Analysis. Amsterdam. University of Amsterdam.

Voce, A. 2005. Handouts for the Qualitative Research Module. London. Sage Publications

Zint, M \& Mongomery, N. 2007. Purposeful Sample. London. Sage Publication 